Original

\title{
Oral lesions associated with HIV infection before and during the antiretroviral therapy era in Ribeirão Preto, Brazil
}

\author{
Alan G. Lourenço'), Ana Carolina F. Motta2), Luis Tadeu M. de Figueiredo1), \\ Alcyone A. Machado1) and Marilena C. Komesu²) \\ 1)Division of Infectious Diseases, Department of Internal Medicine, School of Medicine of Ribeirão Preto, \\ University of São Paulo, Ribeirão Preto, Brazil \\ 2)Department of Morphology, Stomatology and Physiology, School of Dentistry of Ribeirão Preto, \\ University of São Paulo, Ribeirão Preto, Brazil
}

(Received 24 March and accepted 21 July 2011)

\begin{abstract}
We estimated the prevalence of oral lesions associated with human immunodeficiency virus (HIV-OLs) before and during the antiretroviral therapy (ART) era. The first period was 1997, when many patients received two types of antiretroviral (ARV) drugs. The second study period was 2004 through 2008, when all patients were treated with ART (a combination of two or three classes of drugs, including protease inhibitors). A total of 148 and 388 seropositive participants were examined in 1997 and 2004-2008, respectively. The evaluation consisted of anamnesis and physical examination. The prevalence of HIV-OLs decreased between $1997(60.1 \%)$ and 2004-2008 (29.9\%). The HIV-OL responsible for the greatest reduction in prevalence between the two periods was oral candidiasis, of which erythematous candidiasis was the clinical form that decreased most, followed by pseudomembranous candidiasis. In conclusion, we observed a significant reduction in HIV-OLs, which was closely associated with the use of ART. In addition, among patients with a clinical diagnosis of AIDS, we confirmed a significant reduction in HIV-OL prevalence between 1997 and 2004-2008. (J Oral Sci 53, 379-385, 2011)
\end{abstract}

Correspondence to Dr. Alan Grupioni Lourenço, Departamento de Clínica Médica Faculdade de Medicina de Ribeirão Preto - Universidade de São Paulo, Av. Bandeirantes 3900, CEP: 14049900, Ribeirão Preto, SP, Brazil

Tel: $+55-16-3633-0236$

Fax: +55-16-3633-0236

E-mail: alancravinhos@yahoo.com.br
Keywords: AIDS; ART era; HIV; oral lesions; pre-ART era.

\section{Introduction}

Acquired immunodeficiency syndrome (AIDS) is a severe disease and is the late manifestation of human immunodeficiency virus (HIV) infection (1-3). It has been estimated that 33.4 million people are infected by HIV worldwide (4). In Brazil, 544,846 cases were reported from 1980 through 2009 and 217,091 deaths occurred between 1980 and 2008 (5).

In 1986, the capacity of zidovudine (AZT) to inhibit HIV replication was discovered, and the Brazilian government authorized the free distribution of this drug in 1992 (6). In 1996, the efficacy of antiretroviral therapy (ART) in treating HIV was proved. ART, which has been defined as the combination of two or three classes of drugs (7), reduced the number of deaths and significantly increased quality of life among people with AIDS $(8,9)$. In 1996, the Brazilian government signed a law establishing the free distribution of AZT, which gave HIV-seropositive patients access to antiretroviral (ARV) drugs. Later, and particularly after 2001, the Brazilian government was able to markedly reduce the prices of ARV drugs by means of patent infringement. Such efforts further increased the distribution of these medicines by the public health network. The number of patients receiving free ARV drugs through the public health system was 55,600 in 1997, 73,000 in 1999, and approximately 105,000 in 2001 (7). 
Table 1 Characteristics of study participants

\begin{tabular}{lrrrrl}
\hline \multirow{2}{*}{ Characteristics } & \multicolumn{2}{c}{1997} & \multicolumn{2}{c}{$2004-2008$} & \multirow{2}{*}{$P$} \\
\cline { 2 - 5 } & \multicolumn{1}{c}{$n$} & $\%$ & \multicolumn{1}{c}{$n$} & \\
\hline Average age & 33 & & 38 & & $0.0001^{*}$ \\
Duration of seropositivity & 2.8 & & 6 & & $0.0001^{*}$ \\
Men & 93 & $62.8 \%$ & 239 & $61.6 \%$ & 0.7915 \\
Women & 55 & $37.2 \%$ & 149 & $38.4 \%$ & 0.7915 \\
CD4 ${ }^{+}$count & 193 & & 323 & & $0.0001^{*}$ \\
Smoker & 115 & $77.7 \%$ & 169 & $43.6 \%$ & $0.0001^{*}$ \\
Use of ARV & 47 & $31.7 \%$ & 0 & $0 \%$ & $0.0001^{*}$ \\
Use of ART & 18 & $12.2 \%$ & 310 & $79.9 \%$ & $0.0001^{*}$ \\
No ARV/ART & 83 & $56.1 \%$ & 78 & $20.1 \%$ & $0.0001^{*}$ \\
No. of participants & 148 & & 388 & & \\
\hline
\end{tabular}

ARV: antiretroviral, ART: antiretroviral therapy, *statistically significant

In the Clinical Hospital of the School of Medicine of Ribeirão Preto, University of São Paulo, Brazil (CH-SMRP-USP), where this study was conducted, ARV drugs started to be freely and efficiently distributed in 1996. In that year, with the advent of ART, only those patients who were not having good results with one or two ARVs were switched to ART, whereas therapy was unchanged for patients who remained stable on a regimen of one or two ARV drugs. Gradually, the number of patients on ART increased and encompassed nearly all patients receiving ARVs by 2004.

Oral lesions are associated with HIV progression and were described in the first cases of HIV infection $(10,11)$. HIV-associated oral lesions (HIV-OLs) result from reduced immunity among infected individuals, which permits the development of diseases deriving from opportunistic pathogens (12). Sometimes they present as the initial manifestations of AIDS and can precede systemic diseases $(13,14)$. HIV-OLs can also exacerbate systemic symptoms, such as weight loss and diarrhea, that are common among individuals with HIV $(12,15-$ 18). Because many HIV-OLs are easily visualized and diagnosed on the basis of their clinical characteristics, they are excellent indicators of an individual's immune status and permit evaluation of the extent of immunologic involvement (18-21).

The objective of the present study was to compare the prevalence of HIV-OLs during two time periods at CH-SMRP-USP. The first period was 1997, when many of the patients followed at the CH-SMRP-USP received two kinds of ARV drugs and only the most severe cases received ART. The second period was 2004 through 2008, when all patients receiving ARV drugs were treated with ART.

\section{Subjects and Methods}

An epidemiologic study was performed during two time periods to determine the prevalence of HIV-OLs among HIV-seropositive patients that were followed-up at the CH-SMRP-USP. A total of 148 and 388 seropositive participants were examined in 1997 and 2004-2008, respectively, and the participants evaluated in 2004-2008 were not necessarily those who were seen in 1997. The other inclusion criteria were age older than 18 years and data on recent $\mathrm{T}$ CD4 lymphocyte counts $(\mathrm{CD} 4+\mathrm{L}) 3$ months before and 3 months after an oral exam.

The same methodology and same criteria for classification of HIV-OLs were used during both time periods. Evaluation of the participants comprised anamnesis, lymph node palpation, perioral examination, and oral examination. HIV-OLs were identified according to the criteria of the EC-Clearinghouse on Oral Problems Related to HIV Infection and the WHO Collaborating Centre on Oral Manifestations of the Immunodeficiency Virus, 1993 (22). The protocols of these studies were previously approved by the Ethics Committee of CH-SMRP-USP, and all patients gave written informed consent to participate.

Treatment that included one or more antiretroviral agents including nucleosides but excluding protease inhibitors was defined as antiretroviral (ARV) drug treatment, and treatment that included one or more antiretroviral agents plus protease inhibitors was defined as ART.

The software packages GraphPad 3.01 (GraphPad Software Inc., San Diego, CA, USA) and GraphPad Prism 4.00 were used for the statistical analysis. Variables such as age, duration of seropositivity time, and $\mathrm{CD} 4^{+} \mathrm{L}$ count were analyzed using the Student $\mathrm{t}$-test, and data normality was verified using histograms constructed 
Table 2 Numbers of patients with oral lesions in 1997 and 2004-2008

\begin{tabular}{lrrrrrrrr}
\hline \multicolumn{1}{c}{ Oral lesions } & \multicolumn{3}{c}{1997} & \multicolumn{2}{c}{$2004-2008$} & & \multirow{2}{*}{ OR } & 95\% CI \\
\cline { 2 - 7 } & \multicolumn{1}{c}{$n$} & $\%$ & $n$ & $\%$ & & & \\
\hline Erythematous candidiasis & 38 & $25.7 \%$ & 25 & $6.4 \%$ & $0.0001^{*}$ & 5.016 & $(2.900-8.677)$ \\
Pseudomembranous candidiasis & 27 & $18.2 \%$ & 36 & $9.3 \%$ & $0.004^{*}$ & 2.182 & $(1.271-3.745)$ \\
Angular cheilitis & 15 & $10.1 \%$ & 46 & $11.9 \%$ & 0.6828 & 0.8385 & $(0.4527-1.553)$ \\
Hairy leukoplakia & 19 & $12.8 \%$ & 40 & $10.3 \%$ & 0.4953 & 1.281 & $(0.7157-2.294)$ \\
Herpes simplex & 4 & $2.7 \%$ & 3 & $0.8 \%$ & 0.1823 & 3.565 & $(0.7879-16.129)$ \\
Oral ulcers & 4 & $2.7 \%$ & 7 & $1.8 \%$ & 0.7525 & 1.512 & $(0.4359-5.244)$ \\
Oral Kaposi's sarcoma & 0 & $0.0 \%$ & 2 & $0.5 \%$ & 0.9340 & 0.5205 & $(0.02483-10.915)$ \\
Swelling of salivary glands & 1 & $0,7 \%$ & 0 & $0.0 \%$ & 0.6162 & 7.902 & $(0.3198-195.21)$ \\
Multifocal epithelial hyperplasia & 0 & $0.0 \%$ & 1 & $0.3 \%$ & 0.5365 & 0.8698 & $(0.03521-21.488)$ \\
Oral lymphoma & 0 & $0.0 \%$ & 1 & $0.3 \%$ & 0.5365 & 0.8698 & $(0.03521-21.488)$ \\
Oral condyloma & 0 & $0.0 \%$ & 1 & $0.3 \%$ & 0.5365 & 0.8698 & $(0.03521-21.488)$ \\
No. of participants with HIV-OLs** & 89 & $60.1 \%$ & 116 & $29.9 \%$ & $0.0001 *$ & 3.865 & $(2.585-5.777)$ \\
No. of participants & 148 & & 388 & & & & \\
\hline
\end{tabular}

OR: odds ratio, CI: confidence interval

* statistically significant, **Some participants had more than one type of HIV-OL

with the Microsoft Excel program (Microsoft Office Excel 2007, Redmond, WA, USA). Variables such as smoking, sex, ARV/ART use, and presence of HIV-OLs were analyzed using the chi-square test, which was also used to compare HIV-OL prevalence in the two study periods. To measure the correlation between HIV-OLs and different ARV schemes in 1997, we used the chisquare test for independent samples. A $P$ value of 0.05 or less was considered to indicate statistical significance.

\section{Results}

The relevant demographic and clinical characteristics of the seropositive patients, i.e., age, $\mathrm{CD} 4^{+} \mathrm{L}$ count, smoking status, and ARV use, differed between the two study periods; the ratio of men to women was similar (Table 1). The mean age of participants increased from 33 years in 1997 to 38 years in 2004-2008 $(P<0.0001)$. We also observed a significant increase in the time of HIV seropositivity, from 2.8 years in 1997 to 6 years in 2004-2008 $(P<0.0001)$. Average $\mathrm{CD} 4+\mathrm{L}$ count also increased, from 193 cells $/ \mathrm{mm}^{3}$ in 1997 to $323 \mathrm{cells} / \mathrm{mm}^{3}$ in 2004-2008 $(P<0.0001)$.

In 1997, among the 148 patients studied, $93(62.8 \%)$ were men and $55(37.2 \%)$ were women, and the proportions were similar in 2004-2008, when 239 (61.6\%) of the 388 patients studied were men and 149 (38.4\%) were women ( $P=0.7915$; OR, 1.054; 95\% CI, 0.7128-1.559). We also observed a significant reduction in the number of patients who smoked, from 115/148 (77.7\%) in 1997 to $169 / 388(43.6 \%)$ in $2004-2008(P<0.0001$; OR, 4.516; 95\% CI, 2.920-6.984). In 1997, 83/148 (56.1\%) of participants did not receive ARV or ART, 47/148 (31.7\%) received ARVs, and only 18/148 participants (12.2\%) received ART. In 2004-2008, 310/388 (79.9\%) participants received ART and 78/388 (20.1\%) did not.

We observed a significant reduction in the prevalence of HIV-OLs between 1997 and 2004-2008. In 1997, HIV-OL prevalence was $89 / 148$ (60.1\%); in 2004-2008, it was $116 / 388(29.9 \% ; P<0.0001$; OR, 3.865; 95\% CI, 2.585 - 5.777) (Table 2). The most important HIV-OLs detected during both 1997 and 2004-2008 were pseudomembranous candidiasis (PC), erythematous candidiasis (EC), angular cheilitis (AC), hairy leukoplakia (HL), and oral ulcers (OU; Table 2). Oral candidiasis (OC) was the HIV-OL with the greatest reduction in prevalence between the two study periods. Regarding the clinical forms of OC, EC had the greatest reduction in prevalence, from $38 / 148(25.7 \%)$ in 1997 to $25 / 388(6.4 \%)$ in $2004-$ 2008 ( $P<0.0001$; OR, 5.016; 95\% CI, $2.900-8.677)$, followed by PC, the prevalence of which decreased from $27 / 148(18.2 \%)$ in 1997 to $36 / 388(9.3 \%)$ in $2004-2008$ $(\mathrm{P}=0.004$; OR, 2.182; 95\% CI, $1.271-3.745) . \mathrm{AC}$ did not decrease between periods, with $15 / 148$ cases $(10.1 \%)$ in 1997 and $46 / 388(11.9 \%)$ in 2004-2008 $(P=0.6828$; OR, $0.8385 ; 95 \%$ CI, $0.4527-1.553)$.

Although we observed an improvement in patient immunity between 1997 and 2004-2008, HL prevalence did not significantly decrease between periods, with 
Table 3 ARV use and HIV-OLs

\begin{tabular}{|c|c|c|c|c|}
\hline Antiretroviral regimen & Total no. of patients & HIV-OLs (no.) & HIV-OLs & $P$ \\
\hline \multicolumn{5}{|l|}{1997} \\
\hline ARVs & 47 & 36 & $76.6 \%$ & $0.0011 *$ \\
\hline ART & 18 & 14 & $77.8 \%$ & \\
\hline No ARV/ART & 83 & 39 & $47.0 \%$ & \\
\hline \multicolumn{5}{|l|}{ 2004-2008 } \\
\hline ARVs & 0 & 0 & $0 \%$ & \\
\hline ART & 310 & 76 & $24.5 \%$ & $<0.0001^{*}$ \\
\hline No ART & 78 & 40 & $51.3 \%$ & \\
\hline
\end{tabular}

ARV: antiretroviral, ART: antiretroviral therapy, * statistically significant

Table 4 AIDS status and HIV-OLs

\begin{tabular}{|c|c|c|c|c|c|c|}
\hline & No. of participants & HIV-OLs (no.) & HIV-OLs & $P$ & OR & $95 \% \mathrm{CI}$ \\
\hline \multicolumn{7}{|l|}{ No AIDS } \\
\hline 1997 & 15 & 2 & $13.3 \%$ & 0.4561 & 0.5385 & $(0.1038-2.794)$ \\
\hline $2004-2008$ & 45 & 10 & $22.2 \%$ & & & \\
\hline \multicolumn{7}{|l|}{ AIDS } \\
\hline 1997 & 133 & 87 & $65.4 \%$ & $<0.0001^{*}$ & 3.701 & $(2.428-5.642)$ \\
\hline $2004-2008$ & 343 & 116 & $33.8 \%$ & & & \\
\hline
\end{tabular}

OR: odds ratio, CI: confidence interval, * statistically significant

$19 / 148$ cases $(12.8 \%)$ in 1997 and $40 / 388(10.3 \%)$ in 2004-2008 ( $P=0.4953$; OR, 1.281; 95\% CI, 0.7157 2.294). The prevalences of other HIV-OLs were similar in 1997 and 2004-2008.

In 1997, patients who were not receiving ARV/ART had a lower prevalence of HIV-OLs than did those who were $(P=0.0011$; Table 3$)$. In $1997,39 / 83$ (47\%) of patients not receiving ARV drugs developed HIV-OLs, whereas the prevalence of HIV-OLs was higher among patients receiving ART: $77.8 \%$ (14/18). We observed HIV-OLs in $76.6 \%(36 / 47)$ of patients receiving ARVs. In contrast, in 2004-2008, the prevalence of HIV-OLs was higher in patients not receiving ARV or ART $(P<0.0001$; OR, 3.241; 95\% CI, $1.938-5.419)$. Forty (51.3\%) of the 78 patients not receiving ART developed HIV-OLs, and $76(24.5 \%)$ of the 310 participants receiving ART developed HIV-OLs. It is important to mention that the prevalence of HIV-OLs among patients who did not receive $A R V$ s did not change between study periods. In 1997, 39/83 (47\%) patients not receiving ARVs developed HIV-OLs, and a similar prevalence was noted in 2004-2008, when 40/78 (51.3\%) of those not receiving ARVs developed HIV-OLs $(P=0.5860$; OR, 0.8420; $95 \% \mathrm{CI}, 0.4534-1.564)$. Regarding the relation between HIV-OL occurrence and a clinical diagnosis of AIDS, we observed that patients without a clinical diagnosis of AIDS had a similar prevalence of HIV-OLs in both study periods $(P=0.4561$; OR, 0.5385 ; $95 \%$ CI, $0.1038-$ 2.794). In 1997, 2 (13.3\%) of the 15 participants without a clinical diagnosis of AIDS developed an HIV-OL, and in 2004-2008, 10 (22.2\%) of 45 participants without a clinical diagnosis of AIDS developed HIV-OLs. Patients with a clinical diagnosis of AIDS in 1997 had a higher prevalence of HIV-OLs than did those studied in 20042008 ( $P<0.0001$; OR, 3.701; 95\% CI, $2.428-5.642)$. In $1997,87(65.4 \%)$ of the 133 participants with a clinical diagnosis of AIDS developed HIV-OLs, whereas in 2004-2008, the prevalence of HIV-OLs was 116 (33.8\%) of 343 participants (Table 4).

\section{Discussion}

The prevalence of HIV-OLs differs by country. The AIDS epidemic has been discussed in relation to its medical context $(15,23-28)$ and epidemiologic and socioeconomic characteristics (29-31); however, few studies have described the prevalence of HIV-OL in Brazil, especially with regard to changes in the prevalence of HIV-OL that occurred with the advent of ART era (32).

Since 1992, and to a greater extent since 1996, the Ministry of Health has guaranteed free access to ARVs 
for people with AIDS living in Brazil (7,33). In 2001, the Brazilian government infringed patents to obtain a large reduction in the cost of ARVs, from US \$303 million in 2000 to US $\$ 232$ million in 2001 (7).

ART, which began in 1996 after the discovery of new classes of ARVs, eg, protease inhibitors, was the beginning of a new phase in AIDS treatment. It radically changed the quality of life of seropositive patients, because treatment now controlled viral load while drastically decreasing the resistance of HIV to ARVs (34).

In CH-SMRP-USP, the site of the present study, patients started to receive ARVs free of charge in 1996, which was the same year that some patients began ART. However, only patients who did not respond to the use of one or two ARVs received ART. Gradually, ART was provided to all patients who used ARVs. In 1997, most patients on ARVs received a combination of two nucleoside reverse transcriptase inhibitors (NRTIs) - comprising mainly AZT, dideoxyinosine (DDI), and dideoxycytidine (DDC). In 2004-2008, all patients on ARVs received a combination of drugs - an NRTI; a non-nucleoside reverse transcriptase inhibitor (NNRTI), mainly efavirenz and nevirapine; and protease inhibitors (PI), mainly saquinavir, indinavir, ritonavir, nelfinavir, and lopinavir. The quality of life of patients greatly improved with ART, as indicated by the increase in average age from 33 years in 1997 to 38 years in 2004-2008 and by the increase in the duration of HIV-1 seropositivity, from 2.8 years in 1997 to 6 years in 20042008. We also observed an increase in patient immunity: CD4+L count increased from 193 cells $/ \mathrm{mm}^{3}$ in 1997 to 323 cells $/ \mathrm{mm}^{3}$ in 2004-2008. Smoking reduction policies also succeeded in reducing the number of smoking patients from $77.7 \%$ in 1997 to $43.6 \%$ in 2004-2008. The male/female ratio was stable between study periods.

There was a significant reduction in the number of patients with HIV-OLs, from 89/148 (60.1\%) in 1997 to $116 / 388(29.9 \%)$ in $2004-2008$, in agreement with other studies (35-39). In 1997, HIV-OLs were present in patients receiving ARVs, probably because these drugs were mainly given to patients with complications of HIV infection and also because most patients were receiving ARVs rather than ART. Of the 65 participants receiving ARV therapy in 1997, 73\% were receiving ARVs and only $27 \%$ were receiving ART. It is important to mention that the patients receiving ART were those who had not satisfactorily responded to ARVs. Thus, because ART was indicated mainly for the most severe cases, HIV-OLs were predominant in this group in 1997. The opposite situation existed in 2004-2008: all patients receiving ARVs were being treated using the ART scheme. The prevalence of HIV-OLs was $24.5 \%$ (76/310) among patients receiving ART and 51.3\% (40/78) among those not receiving ART. The prevalence of HIV-OLs was similar among patients not receiving ARV: 47\% in 1997 and $51.3 \%$ in 2004-2008. We conclude that the reduced prevalence of HIV-OLs was due to ART use.

The populations studied in 1997 and 2004-2008 differed in age and the proportion of smokers. In 1997 average age was 33 years, while in 2004-2008 it was 38 years. The incidence of oral lesions might be associated with age; however, we believe that a 5 -year difference in age is too small to result in a significant difference.

A 1997 study by Palacio et al. (40) found that smoking was related to increased prevalence of $\mathrm{OC}$ in HIV-seropositive patients; thus, the lower percentage of smokers observed in the present study in 2004-2008 might be associated with the lower prevalence of OC. The oral lesion with the greatest decrease in prevalence was OC, especially the erythematous form (from $25.7 \%$ in 1997 to $6.4 \%$ in 2004-2008) and pseudomembranous form (from 18.2\% in 1997 to $9.3 \%$ in 2004-2008). Many studies have observed a decrease in HIV-OLs with ART use $(37,39,41,42)$. In 2009, Ortega et al. (32) noted a reduction in OC prevalence, from $34 \% 1996$ to just $2.2 \%$ in 2006 among seropositive patients. In a 2007 cohort case-control study in Mexico City, Ramirez-Amador et al. (43) analyzed 1134 individuals and detected a lower OC prevalence among those who were regularly receiving ART. The authors considered the presence of $\mathrm{OC}$ to be an excellent marker of virologic failure in patients receiving ART. Lourenço and Figueiredo in 2008 (23) and Miziara and Weber in 2006 (41) showed that $\mathrm{OC}$ was more prevalent among patients with a low $\mathrm{CD} 4+\mathrm{L}$ count and high viral loads.

We found no reduction in HL prevalence between the two study periods. HL prevalence was $12.8 \%$ in 1997 and $10.3 \%$ in $2004-2008(P=0.4953$; OR, $1.281 ; 95 \% \mathrm{CI}$, $0.7157-2.294)$, in contrasts to the findings of Ortega et al. (2009) (32), who noted a reduction in HL, from $16.3 \%$ in 1996 to $0 \%$ in 2004-2008. We also observed no difference in the prevalence of AC between 1997 and 2004-2008. AC was observed in $15(10.1 \%)$ of 148 participants in 1997 and 46 (11.9\%) of 388 participants in 2004-2008. Although AC is an HIV-OL, other factors such as tooth loss and loss of vertical dimension might have contributed to the persistence of this HIV-OL (44).

In $1997,65.4 \%$ of participants with a clinical diagnosis of AIDS developed HIV-OLs; in 2004-2008, this number decreased to $33.8 \%(P<0.0001)$, which shows the efficacy of ART in decreasing the incidence of HIV-OLs, even among patients with HIV-related complications.

In summary, we observed a significant reduction in 
HIV-OLs, which was closely related to the use of ART. The oral lesion with the greatest decrease in prevalence was oral candidiasis, especially the erythematous and pseudomembranous forms. In addition, we observed a significant reduction in the prevalence of oral lesions in patients with a clinical diagnosis of AIDS.

\section{References}

1. Barré-Sinoussi F, Chermann JC, Rey F, Nugeyre MT, Chamaret S, Gruest J, Dauguet C, Axler-Blin C, Vézinet-Brun F, Rouzioux C, Rozenbaum W, Montagnier L (1983) Isolation of a T-lymphotropic retrovirus from a patient at risk for acquired immune deficiency syndrome (AIDS). Science 220, 868-871.

2. Montagnier L (2002) Historical essay. A history of HIV discovery. Science 298, 1727-1728.

3. Grando LJ, Yurgel LS, Machado DC, Silva CL, Menezes M, Picolli C (2002) Oral manifestations, CD4+ T-lymphocytes count and viral load in Brazilian and North-American HIV-infected children. Pesqui Odontol Bras 16, 18-25.

4. Joint United Nations Programme on HIV/AIDS (2010) Overview of global AIDS epidemic. In: Report on the global AIDS epidemic, 2006, UNAIDS, WHO Library, Geneva, 8-50.

5. Ministério da Saúde, Brasil, Programa Nacional de DST e AIDS (2009) AIDS. In: Boletim Epidemiológico AIDS - ano VI nº.1 julho à dezembro de 2008 / janeiro à julho de 2009, Brasília, 8-29. (in Portuguese)

6. Pinto ACS, Pinheiro PNC, Vieira NFC, Alves MDS (2007) Understanding the AIDS pandemia in last 25 years. J Bras Doenças Sex Trasm 19, 45-50. (in Portuguese)

7. Galvão J (2002) Access to antiretroviral drugs in Brazil. Lancet 360, 1862-1865.

8. Guatelli JC, Siliciano RF, Kuritzkes DR, Richman DD (2002) Human immunodeficiency virus. In: Clinical virology, 2nd ed, Richman DD, Whitley RJ, Hayden FG eds, ASM Press, Washington, 685-729.

9. Dourado I, Veras MA, Barreira D, De Brito AM (2006) AIDS epidemic trends after the introduction of antiretroviral therapy in Brazil. Rev Saude Publica 40, 9-17. (in Portuguese)

10. Greenspan D, Greenspan JS, Conant M, Petersen V, Silverman S Jr, de Souza Y (1984) Oral "hairy" leucoplakia in male homosexuals: evidence of association with both papillomavirus and a herpesgroup virus. Lancet 2, 831-834.
11. Nicolatou O, Nikolatos G, Fisfis M, Belegrati M, Papadaki T, Oikonomaki E, Kalmantis T (1999) Oral hairy leukoplakia in a patient with acute lymphocytic leukemia. Oral Dis 5, 76-79.

12. Hille JJ, Webster-Cyriaque J, Palefski JM, RaabTraub N (2002) Mechanisms of expression of HHV8, EBV and HPV in selected HIV-associated oral lesions. Oral Dis 8, 161-168.

13. Greenspan JS, Greenspan D, Winkler JR (1995) Complicações orais da infecção pelo HIV. In: Tratamento clínico da AIDS, 3rd ed, Sande MA, Volberding PA eds, Revinter, Rio de Janeiro, 125-135. (in Portuguese)

14. Rêgo TITN,Pinheiro ALB (1998) Manifestations of periodontal disease in AIDS patients. Braz Dent J 9, 47-51.

15. Adedigba MA, Ogunbodede EO, Jeboda SO, Naidoo S (2008) Patterns of oral maninestation of HIV/AIDS among 225 Nigerian patients. Oral Dis 14, 341-346.

16. Carpio E, López V, Fardales V, Benítez I (2009) Oral manifestations of HIV infection in adult patients from the province of Sancti Spiritus, Cuba. J Oral Pathol Med 38, 126-131.

17. Gabler IG, Barbosa AC, Velela RR, Lyon S, Rosa CA (2007) Incidence and anatomic localization of oral candidiasis in patients with AIDS hospitalized in a public hospital in Belo Horizonte, MG, Brazil. J Appl Oral Sci 16, 247-250.

18. Coogan MM, Greenspan J, Challacombe SJ (2005) Oral lesions in infection with human immunodeficiency virus. Bull World Health Organ 83,700-706.

19. de Faria PR, Vargas PA, Saldiva PHN, Böhm GM, Mauad T, de Almeida OP (2005) Tongue diseases in advanced AIDS. Oral Dis 11, 72-80.

20. Ranganathan K, Hemalatha R (2006) Oral lesions in HIV infection in developing countries: an overview. Adv Dent Res 19, 63-68.

21. Hodgson TA, Greenspan D, Greenspan JS (2006) Oral lesions of HIV disease and HAART in industrialized countries. Adv Dent Res 19, 57-62.

22. EC-Clearinghouse on Oral Problems Related to HIV Infections and WHO Collaborating Centre on Oral Manifestations of the Immunodeficiency Virus (1993) Classification an diagnostic criteria for oral lesions in HIV infection. J Oral Pathol Med 22, 289-291.

23. Lourenço AG, Figueiredo LTM (2008) Oral lesions in HIV infected individuals from Ribeirão Preto, Brazil. Med Oral Patol Oral Cir Bucal 13, E281-286. 
24. Gaitán-Cepeda LA, Domínguez-Sánchez A, PaviaRuz N, Muñoz-Hernández R, Verdugo-Díaz R, Valles-Medina AM, Meráz-Acosta H (2010) Oral lesions in HIV+/AIDS Adolescents perinatally infected undergoing HAART. Med Oral Patol Oral Cir Bucal 15, e545-550.

25. Giuliani M, Lajolo C, Sartorio A, Ammassari A, Lacaita MG, Scivetti M, Tamburrini E, Tumbarello M (2008) Oral lesions in HIV and HCV co-infected individuals in HAART era. J Oral Pathol Med 37, 468-474.

26. Pedreira EN, Cardoso CL, Barroso Edo C, Santos JAS, Fonseca FP, Taveira LAA (2008) Epidemiological and oral manifestations of HIV-positive patients in a specialized service in Brazil. J Appl Oral Sci 16, 369-375.

27. da Silva CAL, Dourado I, Dahia SR, Harzheim E, Rutherford GW (2008) Oral manifestations of HIV infection in patients receiving highly active antiretroviral therapy (HAART) in Bahia, Brazil. J. Public Health Dent 68, 178-181.

28. Bhayat A, Yengopal V, Rudolph M (2010) Predictive value of group I oral lesions for HIV infection. Oral Surg Oral Med Oral Pathol Oral Radiol Endond 109, 720-723.

29. Gasparin AB, Ferreira FV, Danesi CC, MendozaSassi RA, Silveira J, Martinez AM, Zhang L, Cesar JÁ (2009) Prevalence of oral lesions in person with HIV and associated factors in a southern Brazilian city. Cad Saúde Pública 25, 1307-1315. (in Portuguese)

30. Noce CW, Ferreira SMS, Júnior AS, Dias EP (2009) Association between socioeconomic status and HIV-associated oral lesions in Rio de Janeiro from 1997 to 2004. Braz Oral Res 23, 149-154.

31. Nittayananta W, Chanowanna N, Winn T (2010) Mode of HIV transmission associated with risk of oral lesions in HIV-infected subjects in Thailand. J Oral Pathol Med 39, 195-200.

32. Ortega KL, Vale DA, Magalhães MHCG (2009) Impact of PI and NNRTI HAART, based therapy on oral lesions of Brazilian HIV-infected patients. J Oral Pathol Med 38, 489-494.

33. Fonseca MGP, Bastos FI (2007) Twenty-five years of the AIDS epidemic in Brazil: principal epidemiological findings, 1980-2005. Cad Saúde Pública 23, S333-344.
34. Montagner L (2010) 25 years after HIV discovery: prospects for cure and vacine. Virology 397, 248-254.

35. Greenspan D, Gange SJ, Phelan JA, Navazesh M, Alves ME, MacPhail LA, Mulligan R, Greenspan JS (2004) Incidence of oral lesions in HIV1-infected women: reduction with HAART. J Dent Res 83, 145-150.

36. Flint SR, Tappuni A, Leigh J, Schimidt-Westhausen AM, MacPhail L (2006) (B3) Markers of immunodeficiency and mechanisms of HAART therapy on oral lesions. Adv Dent Res 19, 146-151.

37. Hodgson TA, Naidoo S, Chidzonga M, RamosGomez F, Shiboski C (2006) (A1) Identification of oral health care needs in children and adults, management of oral diseases. Adv Dent Res 19, 106-117.

38. Schmidt-Westhausen AM, Priepke F, Bergmann FJ, Reichart PA (2000) Decline in the rate of oral opportunistic infections following introduction of highly active antiretroviral therapy. J Oral Pathol Med 29, 336-341.

39. Pinheiro RS, França TT, Ribeiro CMB, Leão JC, de Souza IPR, Castro GF (2009) Oral manifestations in human immunodeficiency virus infected children in highly active antiretroviral therapy era. J Oral Pathol Med 38, 613-622.

40. Palacio H, Hilton JF, Canchola AJ, Greenspan D (1997) Effect of cigarette smoking on HIV-related oral lesions. J Acquir Immune Defic Syndr Hum Retrovirol 14, 338-342.

41. Miziara ID, Weber R (2006) Oral candidosis and oral hairy leukoplakia as predictors of HAART failure in Brazilian HIV-infected patients. Oral Dis 12, 402-407.

42. Miziara ID, Weber R (2008) Oral lesions as predictors of highly active antiretroviral therapy failure in Brazilian HIV-infected children. J Oral Pathol Med 37, 99-106.

43. Ramirez-Amador V, Ponce-de-León S, AnayaSaavedra G, Ramirez BC, Sierra-Madero J (2007) Oral lesions as clinical markers of highly active antiretroviral therapy failure: a nested case-control study in Mexico City. Clin Infect Dis 45, 925-932.

44. Kuffer R, Husson C (2000) Superficial cheilitis and angular cheilitis. Ann Dermatol Venereol 127, 88-92. (in French) 